\title{
The Optimization of Genetic Algorithm Based on Hydraulic Cylinder Position of the Exoskeleton Robot
}

\author{
YUE Qingchao \\ Qingdao Huang Hai University, Sanding, 66427, P.R. China \\ 121663260@qq.com
}

\author{
Zheng $\mathrm{Yi}^{\mathrm{a}}$, SU Hang ${ }^{\mathrm{b}}$, ZHONG Peisi ${ }^{\mathrm{c}}$, Liu Kunhua ${ }^{\mathrm{d}}$ \\ College of Mechanical and electrical engineering Shandong \\ University of Science and Technology \\ Shandong, 266590, P.R. China \\ afw.2004@163.com, ${ }^{\mathrm{b}} \mathrm{fw} .2004 @ 163 . c o m$ \\ chhsjzhen@163.com, d2820939503@qq.com
}

\begin{abstract}
Human walking with multiple joints movement, The degrees of freedom is more, Movement is complicated, multiobjective and multiple constraints of continuous function, Common optimization algorithm is required more design variables and large range of computing information, convergence difficulties are existed in these methods, easy to be fell into local extremum, making the optimization results appear deviation. In order to solve optimization problem of continuous function, the mathematical model of hydraulic cylinder and the key joints about exoskeleton robot is established, improved genetic algorithm which combined a nonlinear programming problem with genetic algorithm is applied to optimize exoskeleton mathematical model, the installation position size of the hydraulic cylinder and hydraulic cylinder work pressure was received, And the optimization results are further analyzed to get the final hydraulic cylinder position size.
\end{abstract}

Keywords-The exoskeleton robot; Genetic algorithm; Mathematical model; Nonlinear programming; Optimization

\section{INTRODUCTION}

Using improved genetic algorithm optimization toolbox which combined with a new type of library based on nonlinear programming with MATLAB function and genetic algorithm to optimize.[1] Function of nonlinear programming based on genetic algorithm and optimization algorithm in convergence speed and the result is better than the basic genetic algorithm. According to the theory of genetic algorithm, Using MATLAB software programming to find function optimal solution. Genetic algorithm parameter is set to: population size 100, evolutionary number 30 , crossover probability 0.6 , and mutation probability 0.1 .

\section{A MATHEMATICAL MODEL IS SET UP}

A three hinged point linkage of hydraulic load exoskeleton includes thigh, shank and hydraulic cylinder. It is the core of the whole bearing system. The length and diameter of hydraulic cylinder stroke and the stress of the thighs and legs is determined three hinged point of mechanism design[2].

A four bar linkage of hydraulic load exoskeleton includes thighs; hips support plate, thigh joint bearing and hydraulic cylinder. It is the key mechanism to support weight and flexible movement. Four bar linkage is reasonable or not, determined the stability of the bearing system and the flexibility of the wearer, the size of the hydraulic cylinder pressure change and the length of the trip , directly affects the whole force of the lower extremities and the gait stability and comfort.

\section{A. Determine the design variables}

The installation position of the hydraulic cylinder [3]: Hydraulic cylinder fixed on the underside of the plate, piston cylinder fixed to the back thigh. to determine the distance of fixed point $\mathrm{C}$ to the hip rotation center $\mathrm{O}$ for $\mathrm{X} 1$, the distance of the fixed point $\mathrm{D}$ to rotary center $\mathrm{O}$ for $\mathrm{X} 2$, length of hydraulic cylinder DE as the X3, the fixed point D and rotary center O level Angle for X4.optimization design to X1, X2, X3, $\mathrm{X} 4$, the installation position of the hydraulic cylinder can be positive.

The installation position of the knee joint hydraulic cylinder: the hydraulic cylinder is fixed on the knee joint $A D$, the hydraulic cylinder piston rod is fixed on the $\mathrm{E}$ point of the leg $A B$.Therefore the level of the knee point A rotary center hole D Angle for the X1, the distance of the hydraulic cylinder side mounting holes $\mathrm{D}$ and knee joint rotation center A for $\mathrm{X} 2$, the distance of hydraulic cylinder piston rod fixed installation hole $\mathrm{A}$ and rotary center $\mathrm{E}$ for X3.Optimization design of $\mathrm{X} 1, \mathrm{X} 2, \mathrm{X} 3$, the minimum driving force and the installation location will be given to the vertical hydraulic cylinder of am and cruse activities[4].

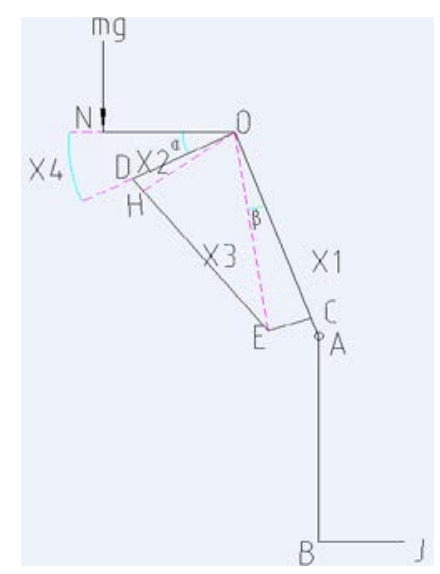

Fig. 1. Hip mechanism simplified diagram 


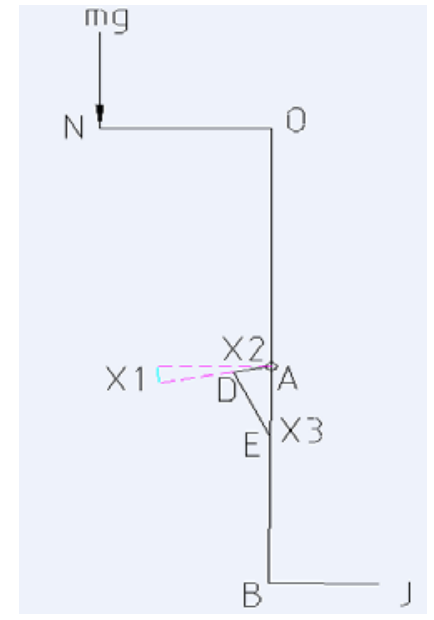

Fig. 2.Knee mechanism simplified diagram

\section{B. Establish a mathematical model of optimization objective function}

The purpose of the hip joint optimization is reasonable hydraulic cylinder installation location. So make sure the hydraulic cylinder pressure $\mathrm{F}$ as the objective function, through force analysis, the hip rotary center $\mathrm{O}$ column moment balance equation, the objective function $\mathrm{F}$ and $\mathrm{X} 1, \mathrm{X} 2, \mathrm{X} 3, \mathrm{X} 4$ are given as follows:

\section{$\mathrm{o}$ a $=0.465$; Thigh length}

a b=0.369; Leg length

c e=0.055; The distance from the hydraulic cylinder piston rod end mounting holes to thigh

$\mathrm{m}=60$; The load weight

$\mathrm{g}=10$; Acceleration of gravity

on=0.212; Focus distance from the center of the hip joint

o c $=\mathrm{x}(1) ; \quad$ Distance from the hydraulic cylinder piston rod end mounting holes to thigh

o $\mathrm{d}=\mathrm{x}(2)$; Hydraulic cylinder barrel end mounting holes distance from the center of the hip joint

$\mathrm{de}=\mathrm{x}(3) ; \quad$ The length of hydraulic cylinder

$\alpha=\mathrm{x}(4)$; The Angle of mounting holes $\mathrm{D}$ point of horizontal and hip center point $\mathrm{O}$

$\beta=x(5) ; \quad$ the Angle between OE and the thighs

$\mathrm{o} e=\sqrt{O C^{2}+C E^{2}}$;

$\gamma=\operatorname{arcos}\left(\left(O E^{2}+O C^{2}-C E^{2}\right) / 2 * O C * C E\right)$;

$\varphi=\operatorname{arcos}\left(\left(O D^{2}+D E^{2}-O E^{2}\right) / 2 * O D * D E\right)$;

oh=o d*sin $(\varphi * \pi)$; $\quad$ The vertical distance from point $\mathrm{O}$ to the hydraulic cylinder

$\mathrm{F}=-\mathrm{m}{ }^{*} \mathrm{~g} * \mathrm{on} / \mathrm{oh}$; The transient hydraulic driving force of hydraulic cylinder

The purpose of the knee joint optimization is reasonable hydraulic cylinder installation location. So make sure the hydraulic cylinder pressure $\mathrm{F}$ as the objective function , through force analysis, the hip rotary center A column moment balance equation, the objective function $\mathrm{F}$ and $\mathrm{X} 1$, X2, X3, X4 are given as follows[5]:

on $=0.212$; Focus distance from the center of the hip joint

o a=0.369; Leg length

$\mathrm{m}=60$; The load weight

$\mathrm{g}=10 ; \quad$ Acceleration of gravity

$\alpha=x(1)$; The Angle of mounting holes $D$ point of horizontal and hip center point $\mathrm{O}$

$\mathrm{ad}=\mathrm{x}(2)$; $\quad$ The distance from hydraulic cylinder barrels of mounting holes $\mathrm{D}$ point to the center of the knee joint $\mathrm{O}$ point

a $\mathrm{e}=\mathrm{x}(3)$; $\quad$ The distance from hydraulic cylinder piston rod end mounting holes to the center of knee $\mathrm{O}$ point[6]

$\mathrm{de}=\sqrt{A D^{2}+A E^{2}-2 * A D^{*} A E}$

$\mathrm{S} \triangle \mathrm{a}$ de $=1 / 2 * \mathrm{AD}^{*} \mathrm{AE} * \mathrm{SIN}(\alpha)$

$\mathrm{ah}=2 * \mathrm{~S} \triangle \mathrm{a}$ de/de; The vertical distance from knee joint center point $\mathrm{A}$ to the hydraulic cylinder

$\mathrm{F}^{*} \mathrm{a} \mathrm{h}+\mathrm{m}^{*} \mathrm{~g}{ }^{*}$ on=0; The moment of knee joint

$\mathrm{F}=-\mathrm{m}^{*} \mathrm{~g}{ }^{*} \mathrm{on} / \mathrm{oh} ; \quad$ The objective function

\section{THE MODIFIED GENETIC ALGORITHM TO OPTIMIZE}

A. Hip hydraulic cylinder mounting holes position optimization:

1) The main function parameter Settings

$\% \%$ main function

\%clear

warning off

$\% \%$ Genetic algorithm parameters

Max gen=150; \% Evolution algebra

size pop $=100 ; \quad \%$ Population size

p cross $=[0.6] ; \quad \%$ Crossover probability

p mutation $=[0.01] ; \quad \%$ Mutation probability

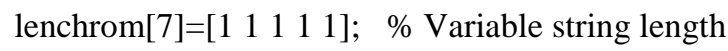

bound=[lo.04 0.1;0.1 0.212;0.3 $0.7 ; 72$ 78;0 15]; \%variable scope

2) The objective function

$\%$ The hydraulic cylinder position optimization

function $\mathrm{f}=\mathrm{o}$ b j fun( $\mathrm{x})[8]$

o a=0.465; \% Thigh length

a b=0.369; \% Leg length

$\mathrm{m}=60 ; \quad \%$ The load weight

$\mathrm{g}=10 ; \%$ Acceleration of gravity

on=0.212; \% Focus distance from the center of the hip joint

a $\mathrm{e}=\mathrm{x}(1) ; \quad \%$ The distance from hydraulic cylinder piston rod end mounting holes to the thigh

o $d=x(2) ; \quad \%$ The distance from Hydraulic cylinder barrel end mounting holes to the center of the hip joint 
$\mathrm{de}=\mathrm{x}(3) ; \quad \%$ The hydraulic cylinder length

gamma $=x(4) ; \quad \%$ the Angle between $\mathrm{OE}$ and the thighs

alpha $=x(5) ; \quad \%$ The Angle between hydraulic cylinder barrels of mounting holes $\mathrm{D}$ point of horizontal and hip center point $\mathrm{O}$

o e=sqrt $\left(\right.$ oa^$^{\wedge} 2+\mathrm{ae}^{\wedge} 2-2 *$ o a*a e* $\cos ($ pi-gamma*pi));

beta $=\operatorname{arcos}\left(\left(\mathrm{oe}^{\wedge} 2+o a^{\wedge} 2-a e^{\wedge} 2\right) / 2 * o\right.$ a*a e);

$\mathrm{S}=1 / 2 *$ o d*o e* $\sin ($ pi/2-alpha*pi-beta);

phi $=\operatorname{arcos}\left(\left(\operatorname{od}^{\wedge} 2+\mathrm{de}^{\wedge} 2-\mathrm{oe}^{\wedge} 2\right) / 2 * o \mathrm{~d}^{*} \mathrm{de}\right)$;

$\mathrm{oh}=\mathrm{o} \mathrm{d} * \sin \left(\mathrm{phi}^{*} \mathrm{pi}\right)$;

$\mathrm{F}=-\mathrm{m}^{*} \mathrm{~g} * \mathrm{on} / \mathrm{oh}$

$\mathrm{f}=\min (\mathrm{abs}(\mathrm{F}))$

3.1.3 Constraint function

function ret $=$ nonlinear(chrom, sizepop)

for $i=1$ :sizepop

$\mathrm{x}=\mathrm{f}$ min con(@objfun, chrom(i,:)',[],[],[],[],[0.04 0.100 .3 72 0],[0.1 0.212 0.778 15]);

$\operatorname{ret}(\mathrm{i},:)=\mathrm{x}^{\prime}$;

end

B. The knee joint hydraulic cylinder mounting holes position optimization:

1) The main function parameter Settings

$\% \%$ Empty the environment

\%clear

warning off

$\% \%$ Genetic algorithm parameters

Max gen=150; \% Evolution algebra

Size pop=100; \% Population size

$\mathrm{P}$ cross $=[0.6] ; \quad \%$ Crossover probability

$\mathrm{P}$ mutation=[0.01]; $\quad \%$ Mutation probability

lenchrom=[1 111$]$; \% Variable string length

bound $=\left[\begin{array}{l}0 \\ 0\end{array}\right.$ 15;0.01 0.05;0.04 0.10]; \% Variable scope

2) The objective function

$\%$ The knee joint optimization

function $\mathrm{f}=\mathrm{ob}$ j fun $(\mathrm{x})$

$\mathrm{M}=48 ; \quad \%$ Knee joint maximum moment

alpha $=45 ; \quad \%$ The Angle between the thighs and legs

beta $=x(1) ; \quad \%$ The Angle between hydraulic cylinder barrels of mounting holes $\mathrm{D}$ point level and the knee joint center point $\mathrm{O}$

ad=x(2); \% The distance from hydraulic cylinder barrels of mounting holes $\mathrm{D}$ point to the center of the knee joint $\mathrm{O}$ point

a $\mathrm{e}=\mathrm{x}(3) ; \%$ The distance from hydraulic cylinder piston rod end mounting holes to the center of $E$ knee $O$ point [9] $\mathrm{de}=\operatorname{sqrt}\left(\mathrm{ad}^{\wedge} 2+\mathrm{ae}{ }^{\wedge} 2-2 * \mathrm{ad}^{*} \mathrm{a} \mathrm{e}^{*} \cos ((\right.$ alpha+beta $\left.) / 180 * \mathrm{pi})\right)$;

$\mathrm{S}=1 / 2 * a \mathrm{~d}^{*}$ a e* $\sin (($ alpha+beta $) / 180 * \mathrm{pi})$; $\mathrm{ah}=2 * \mathrm{~S} / \mathrm{de}$;

$\mathrm{F}=-\mathrm{M} / \mathrm{ah}$;

$\mathrm{f}=\min (\operatorname{abs}(\mathrm{F}))$

C. Constraint function

function ret $=$ nonlinear (chrom, size pop)

for $\mathrm{i}=1$ :sizepop

x=f mincon (@obj fun, chrom(i,:)',[],[],[],[],[0 0.010 .04$],[15$ $0.0350 .16])$;

ret(i,:)=x';

end

\section{THE OPTIMIZATION RESUlt}

After many optimizations, optimization results are obtained as shown in TABLE 1:

TABLE I. THE OPTIMIZATION RESUlTS

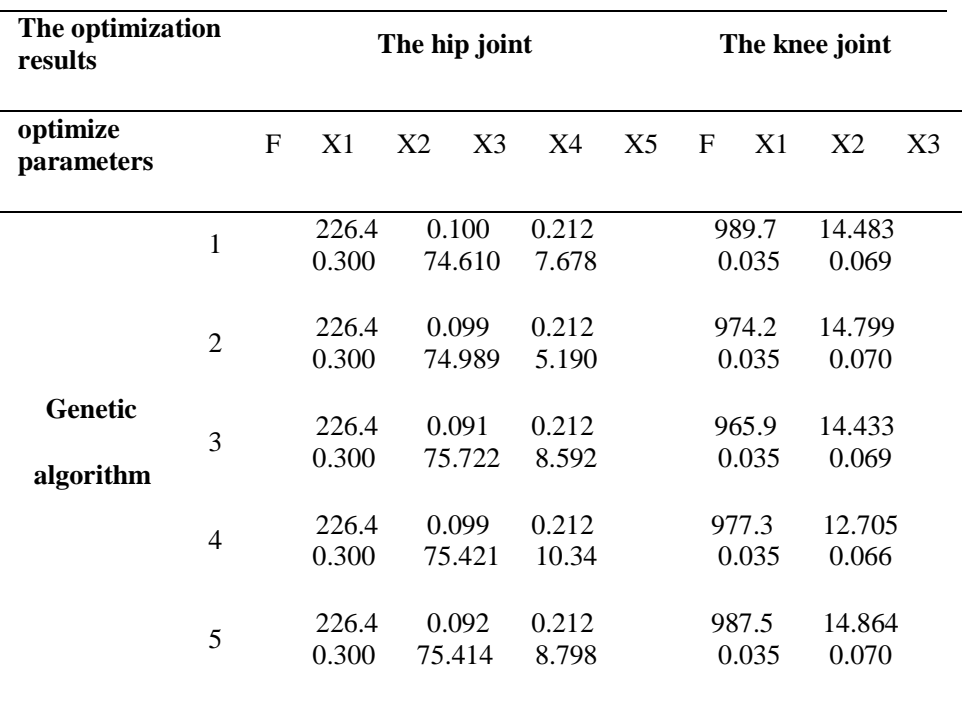

By comparing the optimized algorithm optimization results, and the installation position of the hydraulic cylinder is determine ultimately:

The hip joint:

$\mathrm{X} 1=0.078 \mathrm{X} 2=0.187 \mathrm{X} 3=0.480 \mathrm{X} 4=75.894 \mathrm{X} 5=6.016$

The knee joint:

$\mathrm{X} 1=12.50 \mathrm{X} 2=0.035 \mathrm{X} 3=0.065$

\section{CONCLUSION}

On the basis of the classical genetic algorithm, combined with the nonlinear programming with MATLAB function library function, installation position of hydraulic cylinder is optimized, the optimization results show that the best installation location not only can be determined accurately, but also the optimal working pressure in the process of joint movement of hydraulic cylinder can be determined, It can well meet the needs of the human gait [10]. 


\section{ACKNOWLEDGMENT}

This paper aided financially by Shandong University of Science and Technology plan projects (J16LB58), Shandong Province natural science foundation of China (2016ZRB01AIL), we thanks them greatly and honestly.

\section{REFERENCES}

[1] Aguime-Ollinger G, Colgate JE, Peshkin Metal. A one-degree-offreedom assistive exoskeleton with inertia compensation: the effects on the agility of leg swing motion [J]. Proc Inst Mech. Eng. H, 2011, 225(3): 228-245.

[2] Hu J, Lim YJ, Ding Y et al. an advanced rehabilitation robotic system for augmenting healthcare [J]. Conf. Proc IEEE Eng. Med Biol. Soc., 2011(2011): 2073-2076.

[3] Zhao Nan. Wearable exoskeleton knee three hinged mechanism optimization design[J]. Mechanical engineering and automation, 2012,(1):7-12.
[4] Shine. Lower limbs powered exoskeleton creatures - mechanical system simulation and design of drive unit [D]. Harbin industrial university, 2013.

[5] Cheng Chi-sheng. Exoskeleton lower limb power robotics research [D]. Harbin in Heilongjiang province, Harbin industrial university, 2011.

[6] Zhen-Qing Yang, Su-Kang Cheng. Hierarchical fuzzy neural network control of double inverted pendulum [J]. Journal of motor and control, 2002, 6(3): 245-248.

[7] Chun-min Wang, Hong-Ying Yang. The design of the inverted pendulum control and simulation [J]. Journal of Jilin university (information science edition), 2009, 27(3):242-247.

[8] Ling-Xia Jiao, He-Fang Zhang. Double inverted pendulum fuzzy control research [J]. Journal of electronic design engineering, 2009, 17(10):105107.

[9] Jian-Bin Ye, Hong-Wu Guo. Triple inverted pendulum LQG optimal control scheme of the application research [J]. Journal of computing technology and automation, 2011, 30(4):9-13.

[10] Meng-yin Fu, Zhi-Hong Deng, Ji-Wei Zhang. Kalmar filtering theory and its application in navigation system [M]. Beijing: science press, 2003. 